Leonardo Miessa De Micheli

\title{
BLOCKCHAIN, CRIPTOATIVOS E OS TÍTULOS CIRCULATÓRIOS DO DIREITO COMERCIAL
}

\author{
Tese de Doutorado
}

Orientador: Prof. Titular Newton De Lucca

UNIVERSIDADE DE SÃO PAULO

FACULDADE DE DIREITO

SÃO PAULO - SP

2020 

Leonardo Miessa De Micheli

\section{BLOCKCHAIN, CRIPTOATIVOS E OS TÍTULOS CIRCULATÓRIOS DO DIREITO COMERCIAL}

Tese apresentada à Banca Examinadora do Programa de Pós-Graduação em Direito, da Faculdade de Direito da Universidade de São Paulo, como exigência parcial para obtenção do título de Doutor em Direito, na área de concentração de Direito Comercial, sob a orientação do Prof. Titular Newton De Lucca.

UNIVERSIDADE DE SÃO PAULO

FACULDADE DE DIREITO

SÃO PAULO - SP 
Autorizo a reprodução e divulgação total ou parcial deste trabalho, por qualquer meio convencional ou eletrônico, para fins de estudo e pesquisa, desde que citada a fonte.

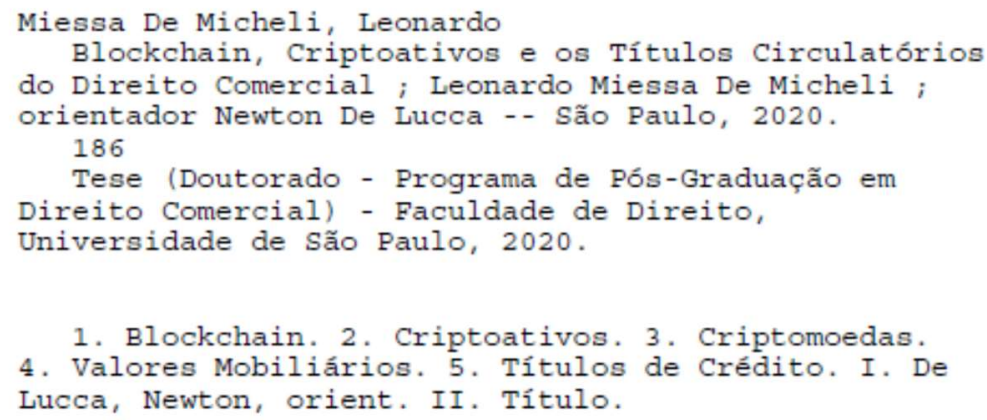


Nome: DE MICHELI, Leonardo Miessa.

Título: Blockchain, Criptoativos e os Títulos Circulatórios do Direito Comercial.

Tese apresentada à Faculdade de Direito da Universidade de São Paulo, Departamento de Direito Comercial, como requisito para obtenção do título de Doutor.

Aprovado em:

Banca Examinadora

Prof. Titular Newton De Lucca

(Presidente da Banca)

Prof. Dr(a):

Instituição:

Julgamento:

Assinatura:

Prof. Dr(a):

Instituição:

Julgamento:

Assinatura:

Prof. Dr(a):

Instituição:

Julgamento:

Assinatura:

Prof. Dr(a):

Instituição:

Julgamento:

Assinatura:

Prof. Dr(a):

Instituição:

Julgamento:

Assinatura: 

DEDICATÓRIA

Para Karina. 



\section{AGRADECIMENTOS}

Ao Professor Titular Newton De Lucca, pela inspiradora orientação oferecida em todo o curso deste doutorado, bem como pela confiança depositada ao acolher um projeto sobre tão nebuloso tema.

Aos Professores Renata Mota Maciel e Roberto Augusto Castellanos Pfeiffer, pelas iluminantes críticas e sugestões trazidas em banca de qualificação, essenciais para o desenvolvimento e conclusão da presente tese.

Aos Professores Juliano Souza de Albuquerque Maranhão, Sheila Christina Neder Cerezetti, Juliana Krueger Pela, Paulo Fernando Campos Salles de Toledo, Vitor Rhein Schirato e Francisco Satiro de Souza Junior, pelas valiosas experiências compartilhadas nas disciplinas cursadas no preenchimento dos créditos da Pós-Graduação.

Aos meus familiares, em especial aos meus pais, Bárbara e Nilton, que acompanharam de forma mais próxima os desafios pessoais decorrentes da realização da presente pesquisa.

Amigos da vida e profissionais, sem exceção, todos foram importantes e de alguma forma contribuíram para conclusão desta etapa, mas especialmente alguns gostaria de citar: Flavia Machado Corchs Daza, Raphael Augusto, Leonardo Barra, Luis Fernando de Lima Carvalho, Leonardo e Angélica Sigollo e Rodrigo Teixeira.

Finalmente, e sem dúvidas o agradecimento mais merecido, à minha esposa, companheira, amiga, parceira, defensora, Karina Corchs. Obrigado, meu amor, pela paciência, apoio, estímulo e, principalmente, por estar sempre ao meu lado. 



\section{EPÍGRAFE}

muitas das forças mais importantes da história são intersubjetivas: leis, dinheiro, deuses, nações. [...] Se eu, sozinho, deixasse de acreditar no dólar, nos direitos humanos ou nos Estados Unidos, não faria muita diferença. [....] uma mudança de tal magnitude só pode ser alcançada com a ajuda de uma organização complexa, como um partido político, um movimento ideológico ou um culto religioso. No entanto, para construir tais organizações complexas, é necessário convencer muitos estranhos a cooperarem uns com os outros (HARARI, 2017). 



\section{RESUMO}

DE MICHELI, Leonardo Miessa. Blockchain, Criptoativos e os Títulos Circulatórios do Direito Comercial. 2020. 186 f. Tese (Doutorado) - Faculdade de Direito, Universidade de São Paulo, São Paulo, 2020.

Na presente tese, busca-se analisar o fenômeno da blockchain e dos criptoativos, desde sua perspectiva genética relacionada ao comportamento social que explicam e justificam seu surgimento e o exponencial crescimento de sua utilização, passando pelas características e soluções técnicas existentes e propostas para as tecnologias de registro distribuído, denominadas Distributed Ledger Technologies, ou simplesmente DLTs, para, finalmente, observar os instrumentos de reflexo econômico suportados em tais plataformas, aqui denominados títulos circulatórios, sob o ponto de vista teórico do Direito Comercial. Para tal objetivo, é proposta uma estruturação teórica sobre os criptoativos, sua natureza jurídica, classificação e o estudo de seu posicionamento em relação a outros institutos do direito, como a moeda, os valores mobiliários e os títulos de crédito, a fim de identificar possíveis enquadramento dos ativos virtuais na tutela jurídica já existente sobre tais tradicionais instrumentos, tanto por sua teoria quanto por sua regulação. Por fim, ainda são analisadas possíveis aplicações da infraestrutura blockchain na criação e circulação de títulos circulatórios tradicionais do Direito Comercial, como valores mobiliários e mercado de capitais, além dos títulos de crédito desmaterializados. Foram utilizadas para o desenvolvimento da pesquisa as metodologias exploratória e empírica, estruturando-se o conteúdo da tese de forma retórica por meio das seguintes grandes premissas: (i) por quê; (ii) como; e (iii) para quê, identificadas nos subtítulos dos 04 Capítulos como: Por que estas tecnologias disruptivas vieram para ficar? Como é possível a tecnologia conferir o elemento essencial da confiança? O que são e em que se aplicam os ativos virtuais e as redes descentralizadas? Quais outros usos das tecnologias de registro descentralizado podem ser úteis aos instrumentos circulatórios de Direito Comercial? Conclui-se, ao final da pesquisa, que a tutela dos criptoativos deve ser considerada com base na função econômica de cada espécie, conforme sugerido nas conclusões, adequando-se as respectivas tutelas regulatórias às peculiaridades de tais instrumentos, tanto genéticas quanto estruturais, sob pena de esvaziamento da própria causalidade existencial dos ativos virtuais.

Palavras-Chave: Blockchain; Criptoativos; Criptomoedas; DLT; Títulos Circulatórios; Valores Mobiliários; Títulos de Crédito; Moeda. 



\begin{abstract}
DE MICHELI, Leonardo Miessa. Blockchain, Crrypto-Assets and Circulatory Instruments from Commercial Law. 2020. 186 f. Thesis (Doctorate) - Faculty of Law, São Paulo University, São Paulo, 2020.

In this thesis, we seek to analyze the phenomenon of the blockchain and the crypto-assets, from their genetic perspective related to social behavior that explains their emergence and the exponential growth of their use, passing through the existing characteristics and technical solutions and proposals for the distributed registration technology systems, called Distributed Ledger Technology, or simply DLT, to finally observe the 'economic impact tools' supported on such platforms, here called 'circulatory instruments', from the theoretical point of view of Commercial Law. For this purpose, it is proposed a theoretical structuring on crypto-assets, their legal nature, classification, and the study of their positioning concerning other assets, such as currency, securities, and negotiable instruments, to identify a possible framework of virtual assets in the already existing legal guardianship on such traditional instruments, both by their theory and by their regulation. Finally, the possible applications of blockchain infrastructure in the creation and circulation of traditional 'circulatory securities' of Commercial Law, such as securities and capital markets, in addition to dematerialized negotiable instruments are also analyzed. Exploratory and empirical methodologies were used for the development of the research, rhetorically structuring the content of the thesis through the following great premises: (i) why; (ii) how; and (iii) so that, identified in the subheadings of the 4 (four) Chapters as; Why are these disruptive technologies here to stay? How can technology provide an essential element of trust? What are virtual assets and decentralized networks, and what they apply to? What other uses of decentralized registration technology systems can be useful to the 'circulatory securities' of Commercial Law? At the end of the research, it is concluded that the protection of crypto-assets must be considered based on the economic function of each type of digital assets, as suggested in the conclusions, adapting the respective regulatory protections to the peculiarities of such instruments, both genetic and structural, under penalty of emptying the very existential causality of virtual assets.
\end{abstract}

Keywords: Blockchain; Crypto-Assets; Cryptocurrencies; DLT; Circulatory Instruments; Securities; Negotiable Instruments; Currency. 



\section{RÉSUMÉ}

DE MICHELI, Leonardo Miessa. Blockchain, Cryptoactifs et Instruments Circulatoires du Droit Commercial. 2020. 186 f. Thèse (Doctorat) - Faculté de Droit, Université de Sao Paulo, Sao Paulo, 2020.

Dans cette thèse, nous cherchons à analyser le phénomène de la blockchain (la chaîne de bloc) et des cryptoactifs, de leur perspective génétique liée aux comportements sociaux, qui expliquent et justifient leur émergence et la croissance exponentielle de leur utilisation, en passant par les caractéristiques et les solutions techniques existantes et les propositions pour les technologies d'enregistrement distribué, appelées Distributed Ledger Technologies, ou tout simplement DLT, pour enfin observer les instruments de réflexe économique supportés sur de telles plateformes, appelés ici titres circulatoires, du point de vue théorique du droit commercial. A cet effet, il est proposé une structure théorique sur les cryptoactifs, leur nature juridique, leur classification et l'étude de leur position par rapport aux autres institutions juridiques, telles que les devises, les valeurs mobilières et les titres de crédit, afin d'identifier d'éventuelles classifications dans le cadre des actifs virtuels dans la protection juridique existante par rapport à ces instruments traditionnels, tant pour leur théorie que pour leur réglementation. Enfin, nous analysons les applications possibles de l'infrastructure blockchain dans la création et la circulation de titres circulatoires traditionnels de droit commercial, tels que les valeurs mobilières et les marchés de capitaux, en plus des titres de crédit dématérialisés. Pour le bon développement de la recherche nous nous sommes servis des méthodologies exploratoires et empiriques structurant le contenu de la thèse de manière rhétorique à travers les grandes prémisses suivantes: (i) pourquoi; (ii) comment; et (iii) pour quoi, identifiées dans les soustitres des quatre chapitres comme: Pourquoi ces technologies perturbatrices sont-elles là pour de bon? Comment la technologie peut-elle fournir l'élément essentiel de la confiance? Que sont les actifs virtuels et les réseaux décentralisés et à quoi s'appliquent-ils? Quelles autres utilisations des technologies d'enregistrement décentralisées peuvent être utiles pour les instruments de circulation du droit commercial? Il est conclu, à l'issue de la recherche, que la tutelle des cryptoactifs doit être considérée en fonction du rôle économique de chaque espèce, comme suggéré dans les conclusions, en adaptant les tutelles réglementaires respectives aux particularités de tels instruments, à la fois génétiques et structurelles, sous peine de vider la causalité existentielle des actifs virtuels. Mots clés: Blockchain; Crypto-actifs; Cryptomonnaies; DLT; Instruments circulatoires; Titres; Instruments négociables; Monnais 



\section{LISTA DE ABREVIATURAS E SIGLAS}

API - Application Programming Interface;

ASEAN - Associação de Nações do Sudeste Asiático;

BCB - Banco Central do Brasil;

BCBS - Comitê de Supervisão Bancária de Basileia;

BCSB - British Columbia Securities Commission;

BID - Banco Interamericano de Desenvolvimento;

CCP - Central Couterparties;

CFTC - Commodity Futures Trading Commission;

COSRA - Conselho de Reguladores de Valores da América;

CPMI - Comitê de Infraestruturas de Pagamentos e Mercados;

CVM - Comissão de Valores Mobiliários;

DAICO - Decentralized Autonomous Initial Coin Offering;

DAO - Decentralized Autonomous Organizations;

DLT - Distributed Ledger Technologies;

DPoS - Delegated-Proof-of-Stake;

EBA - European Banking Authority;

ECG - Enlarged Contact Group on Supervision of Investment Funds;

ESMA - European Securities and Markets Authority;

FATF - Financial Action Task Force,

FCA - Financial Conduct Authority;

FinCEN - Financial Crimes Enforcement Network;

FMI - Fundo Monetário Internacional;

FSAP - Financial Sector Assessment Program;

FSB - Financial Stability Board; 
GAFI/FATF - Grupo de Ação Financeira Internacional;

GAFISUD - Grupo de Integração Financeira da América do Sul contra lavagem de dinheiro e financiamento do terrorismo;

ICO - Inicial Coin Offering;

IIMV - Instituto Ibero-americano de Mercado de Valores;

IOSCO - Organização Internacional de Comissões de Valores;

LADR - Latin American Depository Receipts;

OCDE - Organização para a Cooperação e Desenvolvimento Econômico;

OECD - Organização para Cooperação Econômica e Desenvolvimento;

OMC - Organização Mundial do Comércio;

ONU - Organização das Nações Unidas;

P2P - Peer to Peer;

PBC - People's Bank of China;

PoA - Proof-of-Activity;

PoB - Proof-of-Burn,

PoW - Proof of Stake;

PoW - Proof of Work;

SEC - Securities and Exchange Comission;

STO - Security Token Offering; 


\section{LISTA DE FIGURAS}

Figura 1 - Representação dos sistemas de Luhmann...............................................................42

Figura 2 - Mapa de distribuição geográfica dos usuários full node da blockchain do bitcoin..57

Figura 3 - Representação gráfica de Lessig sob a Lex Cryptographia ....................................92

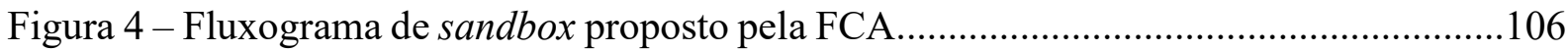

Figura 5 - Fluxograma de sandbox proposto pela CVM....................................................115 



\section{LISTA DE TABELAS}

Tabela 1 - Comparação de Mecanismos de Consenso...........................................................67

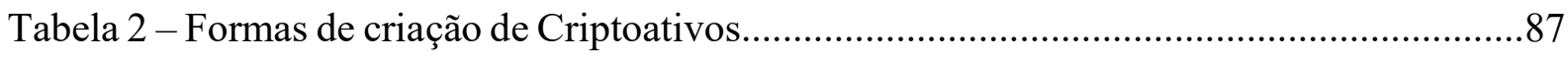





\section{SUMÁRIO}

INTRODUÇÃO.

CAPÍTULO 1 - PREMISSAS E CONTORNOS SOCIAIS SOBRE O FENÔMENO DA BLOCKCHAIN E DOS CRIPTOATIVOS. Por que estas tecnologias disruptivas vieram para ficar?.

1.1 Considerações Iniciais........................................................................... 35

1.2 Sobre a ordem imaginada............................................................................. 35

1.3 O sistema social de Luhmann e a blockchain..................................................... 41

1.3.1 Conceitos do sistema social de Luhmann............................................... 43

1.3.2 Possíveis correlações da teoria dos sistemas sociais e a blockchain........ 44

$1.4 \mathrm{O}$ fim dos intermediários?................................................................................... 46

1.4.1 A descentralização como solução de eficiência X custo........................... 48

1.5. Notas sobre o Capítulo......................................................................................... 51

CAPÍTULO 2 - ASPECTOS TÉCNICOS DA BLOCKCHAIN E SUA CORRELAÇÃo AO COMPORTAMENTO SOCiAL. Como é possível a tecnologia conferir o elemento essencial da confiança? ................................................. 53

2.1 Considerações Iniciais...................................................................................... 53

2.2 Distributed Ledger Technologies ("DLT")........................................................ 53

2.3 Blockchain....................................................................................................... 55

2.3.1 A Tecnologia e a Colaboratividade...................................................... 56

2.3.1.1 O "problema dos 51 por cento".................................................. 60

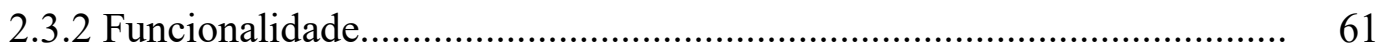

2.3.3 Criação do Bloco de Registro Distribuído................................................ 61

2.3.4 Proof-of-Work (PoW)......................................................................... 63

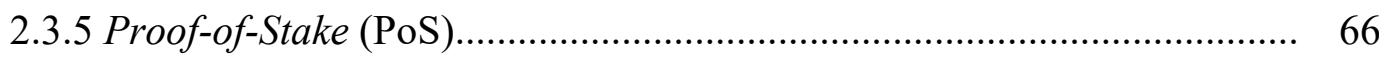

2.3.6 Outros mecanismos de consenso............................................................ 67

2.4 Contratos Inteligentes (Smart Contracts).......................................................... 68

2.5 Notas sobre o Capítulo............................................................................................ 74

CAPÍTULO 3 - A BLOCKCHAIN E OS CRIPTOATIVOS COMO TÍTULOS CIRCULATÓRIOS DO DIREITO COMERCIAL. O que são e em que se aplicam os ativos virtuais e as redes descentralizadas? 
3.1 Considerações Iniciais...................................................................................... 75

3.2 Terminologia e natureza jurídica dos criptoativos......................................... 75

3.3 Classificação dos Criptoativos........................................................................... 79

3.3.1 Criptoativos de Pagamento (Criptomoedas ou Cryptocurrencies)........... 79

3.3.2 Criptoativos de investimento (Security Tokens)................................... 82

3.3.3 Criptoativos de utilidade (Utility Tokens)............................................ 84

3.3.4 Criação e circulação de criptoativos....................................................... 85

3.3.4.1 Inicial Coin Offering (ICO's) e Security Token Offering (STO's).. 85

3.3.4.2 Circulação dos criptoativos: Wallets e Exchanges....................... 88

3.4 A (auto) regulação dos Criptoativos....................................................... 91

3.4.1 As relações internacionais no tratamento dos Criptoativos..................... 95

3.4.2 A regulação estrangeira dos criptoativos.............................................. 98

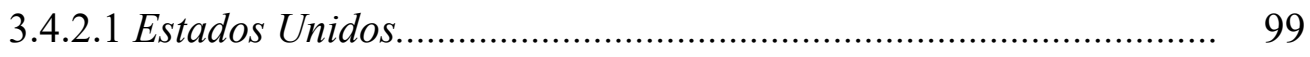

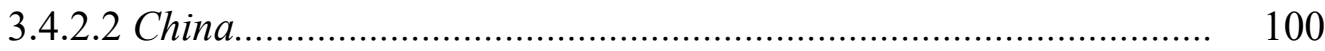

3.4.2.3 União Europeia................................................................... 101

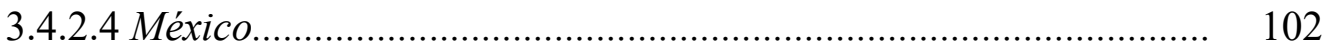

3.4.2.5 A solução via sandboxes........................................................ 104

3.5 A regulação brasileira......................................................................................... 107

3.5.1 Os Projetos de Lei $n^{\circ} 2.303 / 2015$ e 2.060/2019................................... 107

3.5.2 O sandbox da Comissão de Valores Mobiliários.................................... 114

3.6 Análise dos criptoativos com outros institutos de Direito Comercial........... 117

3.6.1 Criptoativos enquanto moedas paralelas.............................................. 117

3.6.2 Criptoativos e os títulos de crédito..................................................... 125

3.6.3 Criptoativos enquanto valores mobiliários........................................ 130

CAPÍTULO 4 - POSSÍVEIS APLICAÇÕES DA BLOCKCHAIN EM OUTROS TÍTULOS CIRCULATÓRIOS. Quais outros usos das tecnologias de registro descentralizado podem ser úteis aos instrumentos circulatórios de Direito

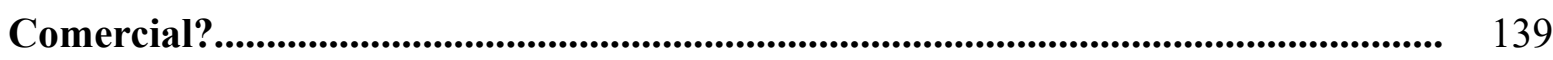

4.1 Considerações iniciais............................................................................. 139

4.2 Aplicações da blockchain no mercado de capitais............................................ 139

4.2.1 Problemas do atual panorama das relações internacionais do mercado de capitais. 
4.2.2 A tecnologia blockchain e a integração internacional do mercado de capitais.

4.3 Aplicações da blockchain em títulos de crédito desmaterializados...............

4.3.1 O uso da blockchain para registro de emissão, endosso e cobrança dos títulos de crédito

4.3.2 Críticas e Sugestões à Lei 13.775/2018 sobre duplicatas virtuais. 



\section{INTRODUÇÃO}

Em 2009, Satoshi Sakamoto (pseudônimo) lança em um fórum público na internet uma nova criação: o bitcoin $^{1}$. Juntamente com o manifesto publicado pela misteriosa figura de Satoshi, o mundo tomava conhecimento da tecnologia de suporte por trás da hoje notoriamente conhecida criptomoeda, criada um ano antes do white paper: a blockchain.

A tecnologia, em suma, é caracterizada por um banco de dados distribuído por toda a rede digital (sistema peer-to-peer), que possibilita a transferência de informações sem a necessidade de um servidor central ou entidade controladora. Cada transação é registrada, verificada e validada em toda a rede, sendo, em tese, virtualmente impossível de ser fraudada.

Como utilidade inicial à blockchain, Sakamoto criou o bitcoin, a primeira moeda virtual da história (e talvez por isso a mais conhecida), ou criptomoeda, cuja emissão não mais seria lastreada pela garantia de veracidade conferida pelo Estado às moedas-fiduciárias, e cuja circulação independeria da intermediação de instituições financeiras.

Contudo, a aplicabilidade das mecânicas extraídas da tecnologia da blockchain e dos criptoativos não se encerraria na existência de uma pretensiosa alternativa ao papel-moeda. Assim, quais seriam os possíveis enquadramentos e utilizações da blockchain e dos, agora mais bem denominados, criptoativos sob o enfoque do Direito Comercial?

O objetivo da presente pesquisa é formular um estudo crítico e analítico do crescente fenômeno tecnológico e social da blockchain e dos criptoativos, confrontando-o com institutos de Direito Comercial já consolidados, a fim de elaborar estudo sistematizado sobre o tema e suas diversas aplicações, com a produção de material acadêmico pouco ou nada explorado no âmbito desta área de concentração.

A prática comercial há algum tempo tem desenvolvido e absorvido novas tecnologias e métodos a fim de otimizar as modalidades de formação de negócios e circulação de riquezas, trazendo nestas inovações relevantes implicações no Direito Comercial.

\footnotetext{
${ }^{1}$ SAKAMOTO, Satoshi. Bitcoin: A Peer-to-Peer Electronic Cash System. Bitcoin.org, 2009. Disponível em: https://bitcoin.org/bitcoin.pdf. Acesso em: 15 out. 2020. Nota: muito se indaga sobre a suposta identidade do autor do citado manifesto, sendo que até a data da elaboração da presente tese não há evidência inequívoca sobre o desenvolvedor original da tecnologia, ou mesmo tratar-se de um grupo de pessoas.
} 
Como tivemos a oportunidade de destacar em dissertação de mestrado ${ }^{2}$, é função histórica do Direito Comercial o dever de fomentar, ao máximo, a adaptação dos institutos por ele tutelados, de maneira a possibilitar que os princípios e normas de direito não se tornem desconexos da realidade social e econômica a que se destinam, e ao mesmo tempo não se mostrem frágeis em suas bases fundamentais, a preservar a segurança que se espera de um sistema jurídico.

Historicamente, como ressalta Ascarelli (1999), o Direito Comercial detém em sua gênese a capacidade de criação de princípios e institutos gerais baseados nas experiências emanadas pelos próprios costumes e práticas surgidas onde antes nada existia.

(...) a sabedoria da elaboração do direito comercial e da obra de seus aplicadores no plano judiciário foi a de haverem superado o interesse de classe. As regras elaboradas para os negócios mercantis dos comerciantes se apresentam, em seu alcance abstrato, como demonstrará a evolução posterior, de aplicabilidade geral e não inspiradas por um interesse de classe que, como tal, exclui uma aplicação geral. São regras independentes do invólucro corporativo com o qual ser originaram, e tendentes a favorecer um desenvolvimento geral da riqueza e não grupos restritos. Sob este aspecto, o direito comercial, distinguindo-se dos vários direitos particulares de classes e territórios, afirma-se como especial no sentido que lembramos há pouco, ou seja, como elaborador de princípios e institutos, suscetíveis de aplicação geral. $^{3}$

Nesta seara, justifica-se o escopo e, desde já, a originalidade da presente pesquisa, na medida em que se mostra necessário o enfrentamento objetivo e conceitual sobre o tema, a fim de buscar-se a compreensão do fenômeno social relativo a blockchain e aos criptoativos, bem como a mais adequada possível interpretação jurídica de suas aplicações e, finalmente, seu confrontamento com os diversos institutos de Direito Comercial.

Trata-se, evidentemente, de inovações tecnológicas, decorrentes de estruturas comportamentais, sociais e, consequentemente, com reflexos jurídicos nas relações dessas decorrentes, sob as quais não poderia a academia comercialista deixar de se debruçar a fim de identificar a real natureza de tais elementos e como se relacionam com os instrumentos comerciais e financeiros tradicionalmente já conhecidos.

\footnotetext{
${ }^{2}$ DE MICHELI, Leonardo Miessa. As duplicatas virtuais como forma de relativização ao princípio da cartularidade. 2014. Dissertação (Mestrado em Direito Comercial) - Faculdade de Direito, Universidade de São Paulo, São Paulo, 2014, p. 154.

${ }^{3}$ ASCARELLI, Tullio. Origem do Direito Comercial, tradução e notas: Fabio Konder Comparato. Revista de Direito Mercantil, Industrial, Econômico e Financeiro, nº 103, Julho-Setembro 1996, p. 98.
} 
As novas tecnologias de rede, suas aplicações industriais e comerciais, como já antecipado por Newton De Lucca $(2000)^{4}$, vêm se desenvolvendo em progressão geométrica e hiatos temporais cada vez mais curtos, exigindo dos acadêmicos e pesquisadores do Direito a árdua tarefa de acompanhar tal ritmo nas respostas das ciências sociais aplicadas.

Como em tantas outras oportunidades, a inércia jurídica (ASCARELLI, 1969) é novamente colocada à prova, a fim de serem revisitados ou ressignificados os institutos jurídicos "ao intuito de conciliar as novas exigências da vida prática com a certeza e a segurança da disciplina jurídica, com a continuidade do desenvolvimento histórico do direito" 5 . O festejado comercialista não poderia ser mais assertivo ao indicar a árdua e recorrente missão do Direito Comercial.

Ressalte-se, ainda, que a originalidade indicada no estudo proposto reside na escassa ou inexistente presença de estudos acadêmicos direcionados especificadamente ao tema na esfera jurídica, em especial na área do Direito Comercial, além da utilização da perspectiva de observação da conduta social aplicada no uso das tecnologias e institutos analisados.

A despeito de diversos estudos e artigos identificados sob o ponto de vista tecnológico, econômico e financeiro, não se localizam estudos aprofundados sobre o crescente fenômeno pelo enfoque da visão do Direito, o que, a se justificar pelo alcance inegável da tecnologia da blockchain e dos criptoativos, se mostra tarefa imprescindível.

\footnotetext{
4 "Não será dificil observar que a progressão geométrica do desenvolvimento tecnológico é acompanhada pela efetiva diminuição do tempo que se interpõe entre uma descoberta científica e sua correspondente exploração industrial". DE LUCCA: Títulos e Contratos Eletrônicos: o advento da Informática e seu impacto no mundo jurídico, in DE LUCCA, Newton; e SIMÃO FILHO, Adalberto (Coord.), Direito \& Internet - aspectos jurídicos relevantes. Bauru, Edipro, 2000, p. 24. Nota: Na atualização da obra mencionada, o título original do texto em referência fora alterado para "Títulos e Contratos Eletrônicos: o advento da Informática e suas consequências para a pesquisa jurídica". O autor justifica a substituição do termo "impacto", por meio das pertinentes considerações: "Como já tive a ocasião de assinalar em outro estudo bem mais recente, reconheci expressamente ter-me deixado influenciar, erroneamente, pela excessiva recorrência da expressão 'impacto' para designar o fenômeno da Sociedade da Informação. Resolvi abandonar definitivamente o seu emprego, porém, a partir das ponderabilíssimas razões do filósofo francês Pierre Lévy, em uma de suas fundamentais obras sobre a matéria, que pôs em realce a inadequação da metáfora do impacto das novas tecnologias na sociedade, formulada nos seguintes termos: 'Nos textos que anunciam colóquios, nos resumos dos textos oficiais ou nos artigos da imprensa sobre o desenvolvimento da multimidia, fala-se muitas vezes no 'impacto' das novas tecnologias da informação sobre a sociedade ou a cultura. A tecnologia seria algo comparável a um projétil (pedra, obus, míssil?) e a cultura ou a sociedade a um alvo vivo...Esta metáfora bélica é criticável em vários sentidos. A questão não é tanto avaliar a pertinência estilística de uma figura de retórica, mas sim esclarecer o esquema de leitura dos fenômenos - a meu ver, inadequado - que a metáfora do impacto no revela". DE LUCCA, Newton. Títulos e Contratos Eletrônicos: o advento da Informática e suas consequências para a pesquisa jurídica, in Direito \& Internet, obra coletiva coordenada por DE LUCCA, Newton e SIMÃO FILHO, Adalberto, Ed. Quartier Latin, $2^{\mathrm{a}}$ ed., São Paulo, 2005, p. 33.

${ }^{5}$ ASCARELLI, Tullio. Problemas das sociedades anônimas e direito comparado. São Paulo: Saraiva, 1969. p. 91.
} 
Importante destacar, neste ponto, não ser o objetivo da presente tese a criação de um novo instituto jurídico ou algo correlato, contudo, a originalidade como requisito acadêmico se verifica no tratamento jurídico sob a perspectiva predominantemente jurídica, em especial sob as premissas do Direito Comercial, porém com relevante carga interdisciplinar na abordagem do conteúdo, notadamente a sociologia, antropologia, ciências econômicas, psicologia e, em menor mas indispensável escala, ciências exatas.

Para tal finalidade, e diante da extrema contemporaneidade do tema abordado, serão utilizadas como metodologias pretendidas ao desenvolvimento da presente tese os métodos exploratório e empírico ${ }^{6}$, a fim de se propor (ou ao menos se intentar) repostas ao final às seguintes indagações, que servirão de linhas-mestre ao trabalho:

(i) Os criptoativos, como hoje conhecidos, estão ou podem ser inseridos no conceito e tratamento de institutos de Direito Comercial tradicionais?

\footnotetext{
${ }^{6}$ Reporta-se empírica a metodologia utilizada, não a nos restringir ao aspecto pragmático do método, mas sim pela sua contribuição à pesquisa por meio da análise e inferência sobre as experiências e práticas comerciais observadas na presente tese, em especial sob o aspecto qualitativo destas e da possibilidade de subsunção aos institutos jurídicos de Direito Comercial consolidados. Tal método, mais comum nas pesquisas acadêmicas das áreas de ciências biológicas e exatas, tem sido largamente utilizado nas pesquisas de ciências sociais aplicadas e, como mencionado por Lee Epstein e Gary King, em trabalho originalmente publicado pela The University of Chicago Law Review, norteia a análise dos fatos do mundo com preponderância da observação e experiência: "Assim como a pesquisa em ciências sociais e naturais comporta uma ampla ordem de problemas teóricos, metodológicos e substanciais, o mesmo ocorre com os estudos produzido por juristas. Os periódicos jurídicos estão repletos de artigos, que variam dos normativos aos descritivos, das análises doutrinárias estritas às investigações estatísticas com amostragem de grande tamanho (grande- $n$ ). Alguns estudos defendem uma reforma legal; outros pretendem apenas ser agregados ao reservatório da literatura jurídica. Mesmo com toda essa variação de abordagens, com toda essa diversidade de propósitos, efeitos e mesmo público-alvo, muitos, se não a maioria, desses estudos apresentam uma característica comum: uma preocupação, mesmo que implícita, com empirismo - baseando conclusões em observação ou experimentação - e inferência- usando fatos conhecidos para aprender sobre fatos que desconhecemos. Esta pode parecer uma afirmação intrigante, mesmo estranha, para os juristas. Nessa comunidade, a palavra "empiricico" passou a possuir um significado particularmente restrito - associado puramente com "técnicas e análises estatísticas" ou com dados quantitativos. Mas a pesquisa empírica, como cientistas naturais e sociais reconhecem, é muito mais ampla do que essas associações sugerem. A palavra "empírico" denota evidência sobre o mundo baseada em observação ou experiência. Essa evidência pode ser numérica (quantitativa) ou não-numérica (qualitativa); nenhuma é mais "empírica" que a outra. O que faz uma pesquisa ser empírica é que seja baseada em observações do mundo - em outras palavras, dados, o que é apenas um termo para designar fatos sobre o mundo. Esses fatos podem ser históricos ou contemporâneos, ou baseados em legislação ou jurisprudência, ou ser o resultado de entrevistas ou pesquisas, ou os resultados de pesquisas auxiliares arquivísticas ou de coletas de dados primários. Os dados podem ser precisos ou vagos, relativamente certos ou muito incertos, diretamente observados ou conseguidos indiretamente; podem ser antropológicos, interpretativos, sociológicos, econômicos, jurídicos, políticos, biológicos, fisicos ou naturais. Desde que os fatos estejam de alguma maneira relacionados ao mundo, eles são dados, e, contanto que a pesquisa envolva dados que são observados ou desejados, ela é empirica". EPSTEIN, Lee; KING, Gary. Pesquisa empírica em direito: as regras de inferência. São Paulo: Direito GV, 2013. p. 11/12.
} 
(ii) A tecnologia blockhain pode ser inserida no contexto de institutos de Direito Comercial, como mercado de capitais e títulos de crédito, sem prejuízo de suas características essenciais? Caso positivo, quais aplicações podem ser identificadas ou potencialmente aplicáveis

Para atingir os objetivos almejados, a presente tese é dividida em quatro capítulos, sendo o primeiro dedicado a inter-relação do fenômeno dos criptoativos e os aspectos de comportamento social que justificam seu surgimento, sustentação e alta popularidade entre os agentes de mercado.

O segundo capítulo é dedicado à metodologia de exploração sobre os aspectos e características técnicas acerca da blockchain e dos criptoativos, relevantes para a pesquisa, uma vez que a abordagem pretendida exige, minimamente, a compreensão das ferramentas e aplicações tecnológicas que vêm sendo inseridas no ambiente comercial.

No terceiro capítulo, buscar-se-á, utilizando-se da melhor compreensão sobre os criptoativos a ser desenvolvida no capítulo, um estudo comparativo destes com instrumentos do Direito Comercial tradicionalmente já conhecidos, a fim de verificar a viabilidade/conveniência de sua inserção em determinada tutela institucional científica já existente.

No quarto e derradeiro capítulo, serão exploradas as possíveis utilizações da blockchain em instrumentos derivados de institutos de Direito Comercial, já em prática ou potenciais, em especial aqueles aos quais a circulação de créditos ou direitos lhes é característico.

Com tal divisão lógica da presente tese, pretende-se uma abordagem retórica a permitir o desenvolvimento por meio das seguintes grandes premissas sobre a análise científica da criação, estrutura e função das tecnologias e plataformas objeto desta pesquisa: (i) por quê; (ii) como; e (iii) para quê, identificadas nos subtítulos dos Capítulos como: Por que estas tecnologias disruptivas vieram para ficar? Como é possível a tecnologia conferir o elemento essencial da confiança? O que são e em que se aplicam os ativos virtuais e as redes descentralizadas? Quais outros usos das tecnologias de registro descentralizado podem ser úteis aos instrumentos circulatórios de Direito Comercial? 
Ao final, serão apresentadas as possíveis conclusões e proposições de respostas às indagações formuladas, no intuito de contribuir com o avanço das pesquisas do novíssimo tema ora enfrentado ${ }^{7}$.

\footnotetext{
${ }^{7}$ Nota: Não se ignorando os relevantes impactos das normas relativas à Lei Geral de Proteção de Dados (Lei 13.709/2018), recentemente promulgada e em eminente início de vigência, aos diversos aspectos do tema objeto da presente tese, ressalva-se não estar em seu escopo a abordagem das extensas nuances das obrigações e regras criadas pela nova legislação aos objetos do presente estudo, na medida em que se busca nesta pesquisa uma análise conceitual, estrutural e funcional dos tipos jurídicos decorrentes das tecnologias indicadas, notadamente a blockchain e os criptoativos nela suportados. Compreendendo não haver prejuízo ao processo metodológico e nos objetivos ora delineados na tese, indica-se, desde já, a necessidade de aprofundamento do estudo acadêmico das regras de conduta emanadas pelo sistema jurídico específico da proteção de dados e sua inegável influência na administração das tecnologias e sistemas ora propostos, contudo, tal análise demanda uma perspectiva específica e estruturalmente própria, cujo escopo foge aos limites propostos na presente pesquisa sem que, ao nosso sentir, haja qualquer prejuízo ao seu desenvolvimento e conclusões.
} 


\section{CONCLUSÕES}

No Capítulo 1, buscou-se analisar, principalmente, todos os aspectos subjetivos que influenciaram o surgimento e a consolidação das redes de registro descentralizadas, nas quais se insere a blockchain, as compreendendo enquanto fenômeno sociológico de forma tão relevante quanto suas atribuições tecnológicas.

Logrou-se interpretar, por meio de teorias sociológicas, em especial das concepções utilizadas sobre intersubjetividade e pela teoria dos sistemas sociais de Luhmann, ser possível firmar uma analogia entre conceitos teóricos das sociedades e premissas fundamentais dos sistemas de redes descentralizadas, baseado nas mecânicas de seu funcionamento e influência de seus personagens.

No mesmo sentido, buscou-se determinar a inter-relação entre o interesse lógico intersubjetivo em um sistema mais eficiente e menos suscetível a vícios decorrentes da concentração de poderes político e/ou econômicos, com a identificação da confiança, compreendida como elemento fundamental para legitimação de qualquer instituto com efeitos jurídicos.

Ainda, para fins de manutenção da linha racional e da metodologia de pesquisa, buscou-se sustentar enquanto teoria os sistemas sociais conforme definição de Luhmann, com a finalidade de contribuir com as concepções teóricas fundamentais possivelmente aplicáveis às tecnologias de rede descentralizadas.

Em contribuição ao desenvolvimento da linha lógico-dedutiva mantida na pesquisa, foram analisados dados estatísticos acadêmicos em estudos sobre eficiência e economia, os quais demonstraram que além das aferições subjetivas no sentido de aceitação e viável legitimação das redes de registros descentralizados, como a blockchain, as experiências sobre a viabilidade financeira de tais mecânica fundamental têm se mostrado realística em curto e médio prazo.

Dadas as evidentes limitações técnicas naturalmente esperadas do pesquisador de ciências sociais sem formação prévia em linguagem de programação ou sistemas de informação, buscou-se no Capítulo 2 a compreensão e análise sistemática de conceitos e elementos essenciais dos suportes tecnológicos sob estudo. 
Foram analisados, portanto, os elementos necessários para formação de uma racionalidade estruturalmente jurídica sobre os instrumentos financeiros e comerciais abordados no decorrer da presente tese, sendo certo que, à despeito da impossibilidade de esgotamento de toda a extensão e complexidade tecnológica que os envolvem, uma mínima e criteriosa interpretação de sobre tais funcionalidades se mostrou tarefa indispensável aos objetivos da presente tese.

Conforme a análise proposta, foi possível aferir pelo método exploratório utilizado que as redes DLTs, ou blockchains, sejam elas abertas ou fechadas, são capazes de conferir segurança e confiança como plataforma de manutenção de registros de operações em dois aspectos:

(i) objetivo e tecnológico: na medida em que o sistema é capaz de manter registros em alto grau de segurança criptográfica, além de sua pulverização de manutenção em cópias idênticas de forma distribuída entre todos usuários da rede, tornando virtualmente impossível a destruição ou corrupção dos dados; e

(ii) intersubjetivo: enquanto proposta a sua correlação estrutural à teoria dos sistemas sociais de Luhmann, bem como os elementos subjetivos apontados no Capitulo 1, a lhe conferir a força atribuída às realidades imaginadas, ou seja, redes intangíveis de comunicação explicadas exclusivamente pelo fenômeno da confiança construída socialmente, mas capazes de atribuir segurança sobras as expectativas de sua infalibilidade.

No Capítulo 3, buscamos a efetiva análise empírica sobre os criptoativos, intrinsicamente relacionados à concepção, estrutura e finalidades das blockchains, sua correlação com as teorias sobre a moeda e aos títulos circulatórios do Direito Comercial, a fim de conferir uma proposição teórica sobre tais ativos virtuais.

É sugerida uma tutela específica aos criptoativos, pois a mera replicação das regras sobre valores mobiliários indica afastar o interesse nos ativos criados justamente em consequência dos defeitos destes institutos. Conforme estruturação desenvolvida no capítulo, buscou-se desenhar um posicionamento dos criptoativos inseridos na tutela do Direito Comercial, em especial no conceito dos títulos circulatórios, depurando-se sua classificação e uma análise comparativa aos instrumentos comerciais tradicionais. 
Por fim, no derradeiro Capítulo 4, foram analisadas e propostas possíveis aplicações da blockchain aos ambientes de circulação dos títulos tradicionais de direito comercial, notadamente os valores mobiliários e respectivo mercado de capitais, além dos títulos de crédito desmaterializados.

Diante de tais apurações, podemos sugerir as seguintes respostas às perguntas formuladas na introdução da presente tese, utilizadas como linhas mestre do desenvolvimento da pesquisa, a começar pela primeira: (i) os criptoativos, como hoje conhecidos, estão ou podem ser inseridos no conceito e tratamento de institutos de Direito Comercial tradicionais?

Sobre tal pergunta, a pesquisa indica que os criptoativos devem ser divididos em 03 espécies: criptoativos de pagamento ou criptomoedas (Cryptocurrencies); criptoativos de investimento (Security Token); e criptoativos de utilidades (Utility Tokens).

Sobre os criptoativos de utilidade, concluímos estarem, em princípio, excluídos das tutelas jurídicas mais rígidas em termos de regulação e controle, por não caracterizarem essencialmente uma representação de valor financeiro.

Contudo, há que se ter cuidado ao categorizar determinado criptoativos em tal classificação, uma vez que o valor subjetivo agregado ao token pode tornar o ativo extremamente relevante sob a perspectiva do interesse dos adquirentes e sua circulação.

Se sua função for única e exclusiva de acesso à ambientes eletrônicos relativos ao criptoativo a que o token se refere, eventuais fóruns de deliberação em decisões de programação sobre as plataformas DLTs que suportam os criptoativos etc., poder-se-á considerá-lo exclusivamente como Utility Token.

Porém, enquanto idealizado como um token de direito à aquisição antecipada ou com aplicação de desconto a um determinado produto ou serviço, ou mesmo possibilidade de preferência na aquisição de outros criptoativos, seu caráter se assemelha a outros institutos, como opções de compra, podendo determinar sua tutela regulamentar e jurídica de forma mais rígida, remetendo-os a depender da efetiva função econômica do ativo à tutela dos valores mobiliários. 
Quanto às criptomoedas, conforme os elementos apurados no item 3.3.1, nos indicam haver a formação de um valor de medida unitária, suficiente nela mesma e que, apesar de sofrer oscilações de mercado de oferta e procura, a caracterizem como um ativo de valor individualizado, permitindo concluir que sua natureza pode compreender dois institutos, a depender da sua forma de utilização: sua caracterização como moeda paralela, instituto social e jurídico já conhecido, se utilizado para pagamentos ou trocas; ou como commodities se utilizado como reserva para mera expectativa de valorização.

Concluindo-se pelo valor jurídico e financeiro do hoje inequívoco volume de operações envolvendo as criptomoedas, e sendo os institutos dos instrumentos supra destacados tutelados pelo Direito Econômico e Financeiro, indica-se mais adequado o tratamento científico mais específico sobre tais ativos por esta área do conhecimento.

No que se refere aos criptoativos de investimento, concluímos pela sua diferenciação essencial das criptomoedas, uma vez que nestas últimas não há expectativa de "rendimentos" ou "esforços exclusivos do captador dos recursos ou de uma terceira pessoa", requisitos do inciso IX, do artigo $2^{\circ}$, da Lei $6.385 / 76$ e do howey test, utilizados na presente tese como critérios para verificação de determinado ativo como valor mobiliário.

Assim, admitido o pressuposto subjetivo das funções econômicas como determinante para caracterização de um instrumento como valor mobiliário, temos que os criptoativos de investimento (Security Tokens), segundo os termos propostos na presente tese, conforme item 3.3.2, são contraprestações a um investimento financeiro, com a finalidade de proporcionar ao adquirente a possibilidade de participação dos riscos de lucro ou perdas financeiras do emitente, ou seja, há vinculação direta com a expectativa de resultados ou riscos da atividade do emitente, com adequação perfeita ao teste indicado e aos termos do inciso IX, do $\operatorname{artigo} 2^{\circ}$, da Lei $6.385 / 76$

Assim, como se observa da característica indicada, os criptoativos de investimento se identificam como verdadeiros valores mobiliários nos termos do inciso IX, do artigo $2^{\circ}$, da Lei 6.385/76 e, por consequência, estariam sujeitos à fiscalização e regulamentação da CVM.

Não há, contudo, até o momento de conclusão da presente tese, ao menos no território nacional, notícia de emissão de criptoativos de investimento (Security Tokens) dentro do ambiente regulatório da CVM, o qual não ainda não aprofundou a regulação específica de tais tokens. 
De toda sorte, conforme notícias de instalação de recente ambiente regulatório experimental pela CVM (item 3.5.2), espera-se que tal iniciativa fomente a adesão por parte dos operadores, nacionais e estrangeiros, às novas ferramentas de captação sobre investimento popular para fins do desenvolvimento e financiamento do mercado de inovação, mediante a autorização do órgão regulador e, por outro lado, sejam implementados procedimentos regulatórios mais dinâmicos e adequados às características fundamentais de tais ativos.

Ressalta-se que, admitidos criptoativos de investimento como valores mobiliários, como de fato são, pode-se sugerir, como consta do item 3.3.2, a seguinte classificação: (i) próprios: são aqueles cujo token de participação é concebido e administrado de forma absolutamente virtual, suportados e circulados em plataformas de rede descentralizadas sendo o ativo virtual finalizado e valorizado em si mesmo; (ii) impróprios são tokens de participação virtuais, porém “espelhados” em valores mobiliários tradicionais (debêntures, ações etc), sendo que apesar de serem criados, suportados e circulados em plataformas de rede descentralizadas, o objeto de valor é atrelado ao ativo real representado pelo ativo virtual.

Concluímos que, em relação aos impróprios, sua sujeição deve se dar às regras tradicionais dos ativos aos quais espelham, porém, quanto aos próprios, se mostra relevante que o agente regulador busque tutelas específicas e mais adequadas às suas características fundamentais, sob risco do esvaziamento da própria razão de sua causalidade existencial.

Ainda, conforme item 3.6.2, foi possível distinguir essencialmente os criptoativos dos títulos de crédito, uma vez que o fundamento de confiança dos destes últimos está na força atribuída ao título em si, a lhe permitir cumprir sua função de documentação de uma expressão de crédito passível de facilitada e segura circulação. De outra banda, como foi possível aferir da análise dos criptoativos, a confiança e a segurança não estão relacionadas ao documento, neste caso necessariamente eletrônico, mas sim no sistema descentralizado que os suporta e lhes permite circular.

Esta diferença nuclear já nos permite distinguir os institutos, na medida em que sua construção conceitual e estrutural parte de origens intersubjetivas diversas, não havendo que se cogitar em aplicação das regras consolidadas sobre os títulos de crédito aos criptoativos. 
Também divergem em suas funções econômicas, uma vez que os títulos de crédito representam a documentação de uma relação de crédito e débito, a fim de fomentar a concessão de crédito a prazo de forma a garantir sua satisfação no vencimento ou sua rápida e eficiente execução forçada em caso de inadimplemento. É essencialmente um documento criado, à despeito da evidente característica de circulabilidade, com o objetivo de ser extinto e liquidado em seu vencimento.

Contudo, aproveitando a referência de gênero mais ampla proposta por Paulo Salvador Frontini (item 3.6.2), sugerimos inserir os criptoativos, em seu conceito, finalidade e estrutura, ao gênero dos títulos circulatórios.

Sob tal ótica, à qual inclinamos a concordar, estariam os criptoativos acrescidos ao rol de espécies inseridos no gênero títulos circulatórios, sujeito-os ao seu arcabouço teórico próprio e distinto, porém abarcado em referência de gênero maior e comum aos outros institutos de comerciais como os títulos de crédito e valores mobiliários, inclusive a justificar claramente sua tutela pela área do conhecimento do Direito Comercial.

Assim, concluímos não estarem os criptoativos de qualquer espécie abarcados pelo conceito, estrutura ou funções dos títulos de crédito, posicionando-os de forma equidistante entre estes e aqueles dentro do gênero dos títulos circulatórios.

Em continuidade, concluímos o quanto segue sobre a segunda pergunta formulada em nossa introdução: (ii) a tecnologia blockhain pode ser inserida no contexto de institutos de Direito Comercial, como mercado de capitais e títulos de crédito, sem prejuízo de suas características essenciais? Caso positivo, quais aplicações podem ser identificadas ou potencialmente aplicáveis.

A resposta, conforme indicado no Capítulo 4, se mostra absolutamente positiva. No que se refere ao mercado de capitais, como pôde-se apurar, as tecnologias de suportes de registro descentralizadas, com alto grau de confiabilidade de segurança e receptividade de automação são ferramentas úteis e fundamentais para a evolução e manutenção da competitividade do sistema tradicional em face dos novos produtos financeiros desenvolvidos hodiernamente. 
Foi possível apontar, conforme item 4.2, as potenciais vantagens da utilização da plataformas blockchain na administração de registro e circulação de valores mobiliários: (i) redução nos custos de gerenciamento e reconciliação dos dados das operações, em função da simplificação e automação dos processos; (ii) flexibilidade no tempo de compensação; (iii) redução ou eliminação dos riscos de erros de compensação; (iv) liquidação automatizada; (v) titularidade direta dos ativos pelo investidor, ao invés de direitos em relação a um intermediário; (vi) transparência e traceabilidade; e (vii) ampliação da segurança das informações.

Apesar de tais aplicações encontrarem-se no campo hipotético, a capacidade de legitimação da confiança no sistema descentralizado indicada no Capítulo 1, aliado às possibilidades técnicas descritas no Capítulo 2, em especial à amplitude do desenvolvimento dos contratos autoexecutáveis (Smart Contracts, item 2.4), permite vislumbrar a criação de um ecossistema confiável e autossuficiente a proporcionar uma infraestrutura mais avançada em termos de eficiência e segurança.

Em especial, como indicado no item 4.2.1, a maior deficiência apurada no mercado de capitais é a histórica dificuldade de integração no ambiente internacional, impregnado com a burocracia de sistemas locais soberanos e individualizados que impedem uma livre confluência de investimentos de forma segura e dinâmica.

Como proposto na presente tese em seu item 4.2.2, tem-se na utilização de registros descentralizados uma possibilidade nunca antes experimentada no que se refere ao mercado de capitais: uma infraestrutura que nasce e é desenvolvida em ambiente internacionalizado, desprendido de fronteiras territoriais e estatais (partindo da cooperação geral para as estruturas internas), em movimento contrário ao qual foi desenvolvida a relação tradicional (partindo das estruturas internas para uma relação global).

Este movimento inverso (do global ao interno) torna possível um desenvolvimento de um ambiente regulatório e de fiscalização único e autônomo, capaz de facilitar a absorção pelos ambientes internos de forma muito mais assimilável do que se tem observado nos mecanismos tradicionais de cooperação (tratamento nacional, o reconhecimento $\mathrm{e} o$ passaporte), sendo que as maiores dificuldades nestes últimos modelos são justamente as peculiaridades internas de cada país sob as quais seus sistemas de mercado de capitais foram desenvolvidos (cultura, costumes, políticas, religião etc), as quais ficam em muito superadas num sistema que detém em sua essência uma interoperação independente de soberanias. 
Não obstante, foi possível indicar que o sistema de registro descentralizado por meio da blockchain se mostra absolutamente receptivo ao processo de criação, circulação e cobrança dos títulos de crédito, aqui invariavelmente tratadas as modalidades desmaterializadas.

Para tanto, sugeriu-se um modelo proposto, utilizando-se da duplicata virtual como material de ensaio, no qual demonstrou-se viável a sistematização de forma quase integralmente automatizada, com mínima intervenção humana, de toda a cadeia existencial (criação, circulação e cobrança) da duplicata mercantil, sendo certo que a formatação exemplificada (item 4.3.1) pode ser aplicada ou adaptada a toda e qualquer espécie de título de crédito (Notas Promissórias; Cédulas de Crédito Bancários; Títulos do Agronegócio etc), uma vez que preservados todos os elementos jurídicos indispensáveis à sua validade e sua sujeição à teoria geral consolidada sobre o instituto.

Com tais conclusões, apesar do insofismável potencial de novas aplicações das tecnologias abordadas, tanto estruturais quanto conceituais, as quais surgem quase diariamente transformando e desafiando as relações sociais e jurídicas, esperamos ter no desenvolvimento da presente tese, se não esgotado ao menos as questões ora propostas, ter conferido uma legítima contribuição original ao tema em questão, o qual persiste em plena ebulição, certamente a fomentar novas e inúmeras discussões, não só no campo jurídico, mas sim em todas as áreas do conhecimento. 


\section{REFERÊNCIAS}

ALIAGA, Yoshitomi Eduardo Maehara. Estudo sobre mecanismos de consenso de baixo custo para Blockchain. Dissertação (mestrado) - Universidade Estadual de Campinas, Faculdade de Engenharia Elétrica e de Computação, 2019;

AMATO, Lucas Fucci; BARROS, Marco Antonio Loschiavo Leme de (Orgs.). Teoria crítica dos sistemas: crítica, teoria social e direito [recurso eletrônico]. Porto Alegre, RS: Editora Fi, 2018;

An Introduction to Hyperledger. Disponível em: https:/www.hyperledger.org/wpcontent/uploads/2018/07/HL_Whitepaper_IntroductiontoHyperledger.pdf. Acesso em: 15 out. 2020;

ASSOCIAÇÃO BRASILEIRA DAS ENTIDADES DOS MERCADOS FINANCEIRO E DE CAPITAIS - ANBIMA. Criptoativos: Introdução sobre os conceitos, usos e responsabilidades associados a esses instrumentos, 2009, p. 3. Disponível em: https://www.anbima.com.br/data/files/17/94/55/B2/2FD8D61078F0C4D69B2BA2A8/Estudo $\% 20$ sobre $\% 20$ Criptoativos $\% 20$ GT\%20ICO\%20e\%20Cripto .pdf. Acesso em: 15 out. 2020.

ASSOCIAÇÃO BRASILEIRA DAS ENTIDADES DOS MERCADOS FINANCEIRO E DE CAPITAIS - ANBIMA. Internacionalização dos mercados financeiro e de capitais brasileiros: diagnóstico e potenciais ações. 2016. Disponível em: http://www.anbima.com.br/data/files/2C/45/E4/E8/0A7B95104FEB5B9568A80AC2/ANBIM A-Estudo-sobre-internacionalizacao-dos-mercados-financeiro-e-de-capitais.pdf. Acesso em: 15 out. 2020 ;

ASCARELLI, Tullio. Origem do Direito Comercial, tradução e notas: Fabio Konder Comparato. Revista de Direito Mercantil, Industrial, Econômico e Financeiro, $n^{\circ}$ 103, JulhoSetembro 1996;

ASCARELLI, Tullio. Problemas das sociedades anônimas e direito comparado. São Paulo: Saraiva, 1969.

ASCENSÃO, José de Oliveira. A Sociedade da Informação, in Direito da Sociedade de Informação, vol. II, Revista da Faculdade de Direito de Lisboa.

AUTHORITY, European Banking. VIRTUAL CURRENCY SCHEMES. 2012. Disponível em: http://www.ecb.europa.eu/pub/pdf/other/virtualcurrencyschemes201210en.pdf. Acesso em: 15 out. 2020 ;

AVGOULEAS, Emilios; KIAYIAS, Aggelos. European Business Organization Law Review (2019) 20: 81. Disponível em: https://doi-org.ezproxy.library.qmul.ac.uk/10.1007/s40804-01900133-3. Acesso em: 15 out. 2020;

AVGOUlEAS, Emilios; KIAYIAS, Aggelos. The Promise of Blockchain Technology for Global Securities and Derivatives Markets: The New Financial Ecosystem and the 'Holy Grail’ of Systemic Risk Containment. Eur Bus Org Law Rev 20, p. 81-110, 2019. p. 102. 
Disponível em: https://link.springer.com/article/10.1007/s40804-019-00133-3 Acesso em: 15 out. 2020;

BANCO CENTRAL DO BRASIL - BCB. Circular no 3.944, de 29 de maio de 2019. Altera a Circular $n^{\circ}$ 3.681, de 4 de novembro de 2013, que dispõe sobre o gerenciamento de riscos, os requerimentos mínimos de patrimônio, a governança de instituições de pagamento e a preservação do valor e da liquidez dos saldos em contas de pagamento. Disponível em: https://www.bcb.gov.br/pre/normativos/busca/downloadNormativo.asp?arquivo=/Lists/Norm ativos/Attachments/50765/Circ 3944 v1 O.pdf. Acesso em: 15 out. 2020;

BANCO CENTRAL DO BRASIL - BCB. Comunicado $n^{\circ} 31.379$, de 16 de novembro de 2017. Alerta sobre os riscos decorrentes de operações de guarda e negociação das denominadas moedas virtuais. Disponível em: https://www.bcb.gov.br/estabilidadefinanceira/exibenormativo?tipo=Comunicado\&numero=3 1379. Acesso em: 15 out. 2020;

BANCO CENTRAL DO BRASIL - BCB. Circular $n^{\circ} 4.016$, de 04 de maio de 2020. Dispõe sobre a atividade de escrituração de duplicata escritural, sobre o sistema eletrônico de escrituração gerido por entidade autorizada a exercer essa atividade e sobre o registro ou o depósito centralizado e a negociação desses títulos de crédito. Disponível em: https://www.bcb.gov.br/estabilidadefinanceira/exibenormativo?tipo=Circular\&numero=4016. Acesso em: 15 out. 2020;

BANCO CENTRAL DO BRASIL - BCB. Comunicado Conjunto Ministério da Economia, Banco Central, CVM e Susep: divulga ação coordenada para implantação de regime de sandbox regulatório nos mercados financeiro, securitário e de capitais brasileiros. 2019. Disponível em: https://www.bcb.gov.br/detalhenoticia/16776/nota. Acesso em: 15 out. 2020;

BANK FOR INTERNATIONAL SETTLEMENTS - BIS; IOSCO. Recommendations for Central Counterparties. Committee on Payment and Settlement Systems. Novembro/2004, p. 3. Disponível em: https://www.bis.org/cpmi/publ/d64.pdf. Acesso em: 15 out. 2020;

BARBER, Simon. et al. Bitter to Better - how to make bitcoin a better currency. San Diego: Palo Alto Research Center and University of California; 2012. Disponível em: http://crypto.stanford.edu/ xb/fc12/bitcoin.pdf. Acesso em: 15 out. 2020;

BRITISH COLUMBIA SECURITIES COMMISSION - BCSB. Disponível em: https://www.bcsc.bc.ca/About Us/. Acesso em: 15 out. 2020;

BEAM. Disponível em: https://beam.mw/. Acesso em: 15 out. 2020;

BECHMANN, Gotthard; STEHR, Nico. Niklas Luhmann. Tempo Social, São Paulo, v. 13, n. 2, 2001;

BLANC, Jérome. Las Monedas Paralelas: Evaluación y Teorías del Fenómeno. 1998, p. 4. Disponível em: http://halshs.archivesouvertes.fr/docs/00/11/16/49/PDF/BlancREF1998EspHAL.pdf. Acesso em: 15 out. 2020; 
BLANDIN, Apolline; et al. Global Cryptoasset Regulatory Landscape Study. University of Cambridge Faculty of Law Research Paper No. 23/2019. 2019, p. 36. Disponível em: https://ssrn.com/abstract=3379219. Acesso em: 15 out. 2020;

BOBBIO, Norberto. Da estrutura à função: estudos de teoria do direito. Tradução Daniela Beccaccia Versiani. Barueri/SP: Manole, 2007.

BOBBIO, Norberto. Dalla Strutura Alla Funzione - Nuovi Studi di Teoria del Diritto. $2^{\text {a }}$ ed. Ed. Di Comunità. Milão. 1984;

BRASIL. Congresso Nacional. Lei Federal no 4.565, de 31 de dezembro de 1964. Dispõe sobre a Política e as Instituições Monetárias, Bancárias e Creditícias, Cria o Conselho Monetário Nacional e dá outras providências. Disponível em http://www.planalto.gov.br/ccivil_03/leis/14595.htm. Acesso em: 15 out. 2020;

BRASIL. Lei Federal $n^{\circ} 4.565$, de 31 de dezembro de 1964. Dispõe sobre a Política e as Instituições Monetárias, Bancárias e Creditícias, Cria o Conselho Monetário Nacional e dá outras providências. Disponível em http://www.planalto.gov.br/ccivil_03/leis/14595.htm. Acesso em: 15 out. 2020;

BRASIL. Lei Federal $n^{0} 5.474$, de 18 de julho de 1968. Dispõe sobre as Duplicatas, e dá outras providências. Disponível em: http://www.planalto.gov.br/ccivil_03/leis/15474.htm. Acesso em: 15 out. 2020;

BRASIL. Lei Federal $n^{\circ} 6.385$, de 07 de dezembro de 1976. Dispõe sobre o mercado de valores mobiliários e cria a Comissão de Valores Mobiliários. Disponível em http://www.planalto.gov.br/ccivil_03/leis/16385.htm. Acesso em: 15 out. 2020;

BRASIL. Lei Federal $\mathrm{n}^{\mathrm{o}} 10.303$, de 31 de outubro de 2001. Altera e acrescenta dispositivos na Lei no 6.404, de 15 de dezembro de 1976, que dispõe sobre as Sociedades por Ações, e na Lei no 6.385, de 7 de dezembro de 1976, que dispõe sobre o mercado de valores mobiliários e cria a Comissão de Valores Mobiliários. Disponível em http://www.planalto.gov.br/ccivil_03/leis/leis_2001/110303.htm. Acesso em: 15 out. 2020;

BRASIL. Lei Federal $n^{\circ} 12.865$, de 09 de outubro de 2013. Dispõe sobre os arranjos de pagamento e as instituições de pagamento integrantes do Sistema de Pagamentos Brasileiro (SPB). Disponível em http://www.planalto.gov.br/ccivil_03/_Ato20112014/2013/Lei/L12865.htm. Acesso em: 15 out. 2020;

BRASIL. Lei Federal $n^{\circ} 13.775$, de 18 de dezembro de 2018. Dispõe sobre a emissão de duplicata sob a forma escritural; altera a Lei $n^{\circ}$ 9.492, de 10 de setembro de 1997; e dá outras providências. Disponível em: http:/www.planalto.gov.br/ccivil_03/_Ato20152018/2018/Lei/L13775.htm. Acesso em: 15 out. 2020;

BRASIL. Projeto de Lei $\mathbf{n}^{\mathbf{0}} \mathbf{2 . 0 6 0 / 2 0 1 9}$. Dispõe sobre o regime jurídico de Criptoativos. Disponível em: https://www.camara.leg.br/proposicoesWeb/fichadetramitacao?idProposicao=2196875.

Acesso em: 15 out. 2020; 
BRASIL. Projeto de Lei $\mathbf{n}^{\mathbf{0}}$ 2.304/2015. Dispõe sobre a inclusão das moedas virtuais e programas de milhagem aéreas na definição de "arranjos de pagamento" sob a supervisão do Banco Central.

Disponível em: https://www.camara.leg.br/proposicoesWeb/fichadetramitacao?idProposicao=1555470.

Acesso em: 15 out. 2020;

BUTERIN, Vitalik. Explanation of DAICOs. 2018. Disponível em: https://ethresear.ch/t/explanation-of-daicos/465. Acesso em: 15 out. 2020;

CAMPOS, Emília Malgueiro. Criptomoedas e Blockchain o direito no mundo digital. Rio de Janeiro: Lumen Juris, 2018;

CARVAlHOSA, Modesto; EIZIRIK., Nelson. Estudos de direito empresarial. São Paulo: Saraiva, 2010;

COMISSÃO DE VALORES MOBILIÁRIOS - CVM. Disponível em: http://www.cvm.gov.br/menu/internacional/atuacao/sobre.html. Acesso em: 15 out. 2020;

COMISSÃO DE VALORES MOBILIÁRIOS - CVM. Fluxograma de Participação no sandbox.

Disponível em:http://www.cvm.gov.br/export/sites/cvm/audiencias_publicas/ap_sdm/anexos/2019/sdm05 19 fluxograma_sandbox_processo_admissao_participantes.jpg. Acesso em: 15 out. 2020;

COMISSÃO DE VALORES MOBILIÁRIOS - CVM. INSTRUÇÃO CVM Nº 626, DE 15 DE MAIO DE 2020. Disponível http://www.cvm.gov.br/legislacao/instrucoes/inst626.html. Acesso em: 15 out. 2020;

COMISSÃO DE VALORES MOBILIÁRIOS - CVM. RELATÓRIO DE ANÁLISE. Audiência Pública SDM no 05/19 - Processo CVM SEI no 19957.008843/2018-11. Disponível em: http://www.cvm.gov.br/audiencias publicas/ap sdm/2019/sdm0519.html. Acesso em: 15 out. 2020;

CONG, Lin William, HE, Zhiguo. Blockchain Disruption and Smart Contracts, The Review of Financial Studies, Volume 32, May 2019, p. 1661/1662. Disponível em: https://academicoup-com.ezproxy.library.qmul.ac.uk/rfs/article/32/5/1754/5427778. Acesso em: 15 out. 2020;

CRIPTOGRAFIA. em Dicionário Priberam da Língua Portuguesa [em linha], 2008-2020. Disponível em https://dicionario.priberam.org/criptografia. Acesso em: 15 out. 2020;

DA COSTA, Everton Garcia; COELHO, Gabriel Bandeira. Para Entender a Sociologia de Niklas Luhmann. Caderno CRH, Salvador, v. 30, n. 81, Set./Dez. 2017;

DATA, Digital Asset Transfer Authority. CONSUMER PRACTICES GUIDELINES. 2010. Disponível em: http://pt.slideshare.net/DataSecretariat/data-working-group-consumer-bestpractices. Acesso em: 15 out. 2020;

DE LUCCA, Newton. A Cambial-Extrato, São Paulo: ed. Revista dos Tribunais, 1985; 
DE LUCCA, Newton. Aspectos da responsabilidade civil no âmbito da internet. In: DINIZ, Maria Helena; LISBOA, Roberto Senise. (coord.). O Direito Civil no Século XXI. São Paulo: Saraiva, 2003;

DE LUCCA, Newton. Aspectos Jurídicos da Contratação Informática e Telemática. São Paulo: Saraiva, 2003;

DE LUCCA, Newton. Títulos e contratos eletrônicos: o advento da Informática e suas consequências para a pesquisa jurídica. in DE LUCCA, Newton; SIMÃO Filho, Adalberto. (coords.) Direito \& Internet: aspectos jurídicos relevantes. 2. ed. São Paulo: Quartier Latin, 2005 ;

DE LUCCA, Newton. Títulos e Contratos Eletrônicos: o advento da Informática e seu impacto no mundo jurídico, in DE LUCCA, Newton; e SIMÃO FILHO, Adalberto (Coord.), Direito \& Internet - aspectos jurídicos relevantes. Bauru, Edipro, 2000;

DE LUCCA, Newton; NAJJARIAN, Ilene Patrícia de Noronha. Criptomoedas: novos meios de pagamento. Direito Tecnologia e Inovação v.I. PARENTONI, Leonardo [Coord.]. GONTIJO, Bruno Miranda; LIMA, Henrique Cunha Souza [Org.]. Belo Horizonte: Editora D’Plácido, 2019;

DE MICHELI, Leonardo Miessa. As duplicatas virtuais como forma de relativização ao princípio da cartularidade. 2014. Dissertação (Mestrado em Direito Comercial) - Faculdade de Direito, Universidade de São Paulo, São Paulo, 2014;

DURAN, Camila Villard; STEINBERG, Daniel Fidelis; CUNHA FILHO, Marcelo de Castro. Criptoativos: o que são e como regular? Recomendações aos Projetos de lei 2060/2019 e 2303/2015. Faculdade de Direito da Universidade de São Paulo, 2019. p. 2. Disponível em: https://www2.camara.leg.br/atividade-legislativa/comissoes/comissoestemporarias/especiais/56a-legislatura/banco-central-regular-moedasvirtuais/documentos/audiencias-publicas/CamilaDuranProfessoraDoutoradaUSP.pdf. Acesso em: 15 out. 2020 ;

EDWARDS, Lilian; WAELDE, Charlotte. Law and the Internet. 3. Ed. Oregon, Oxford and Portland: Hart, 2009;

EPSTEIN, Lee; KING, Gary. Pesquisa empírica em direito: as regras de inferência. São Paulo: Direito GV, 2013;

ESTADOS UNIDOS DA AMÉRICA. TOO BIG TO FAIL, TOO BIG TO EXIST ACT. Disponível em https://www.congress.gov/bill/115th-congress/house-bill/7006/all-info. Acesso em: 23 mai. 2019;

ESTADOS UNIDOS MEXICANOS. Comisión Nacional Bancaria y de Valores. Disposiciones de carácter general aplicables a las Instituciones de Tecnología Financiera. Disponível em: http://www.dof.gob.mx/nota detalle.php?codigo $=5537450 \&$ fecha $=10 / 09 / 2018$. Acesso em: 15 out. 2020

Ethereum Mainnet Statistics. Disponível em: https://www.ethernodes.org/countries. Acesso em: 15 out. 2020; 
ETHEREUM. Disponível em: https://ethereum.org/pt-br/. Acesso em: 15 out. 2020;

EUNÁPIO BORGES, João. Títulos de Crédito, Rio de Janeiro: ed. Forense, 1971;

FAMA, Eugene. Efficient capital markets: II. The Journal of Finance, v. 46, n. 5 p. 1.5751.618, Cambridge, 1991;

FINANCIAL ACTION TASK FORCE - FATF. Guidance for a Risk-Based Approach to Virtual Assets and Virtual Asset Service Providers: Paris: FATF, 2019. Disponível em: http://www.fatf-gafi.org/publications/fatfrecommendations/documents/Guidance-RBAvirtual-assets.html. Acesso em: 15 out. 2020;

FINANCIAL ACTION TASK FORCE - FATF. Methodology for Assessing Compliance with the FATF Recommendations and the Effectiveness of AML/CFT Systems, updated October 2019, FATF, Paris, France, 2019. Disponível em: http://www.fatfgafi.org/publications/mutualevaluations/documents/fatf-methodology.html. Acesso em: 15 out. 2020;

FEIGELSON, Bruno; LEITE, Luiza. Sandbox [livro eletrônico]: experimentalismo no direito exponencial. 1. ed. São Paulo. Thomson Reuters Brasil, 2020;

FINANCIAL STABILITY BOARDER - FSB. Crypto-assets regulators directory. 2019. Disponível em: https://www.fsb.org/wp-content/uploads/P050419.pdf. Acesso em: 15 out. 2020

FINKELSTEIN, Maria Eugênia. Aspectos Jurídicos do Comércio Eletrônico, São Paulo: Thoson-IOB, 2004;

FINTRAC - Financial Transactions and Reports Analysis Centre of Canada. Disponível em: https://www.fintrac-canafe.gc.ca/fintrac-canafe/1-eng. Acesso em: 15 out. 2020;

FISHER, Irving. The Debt-Deflation Theory of Great Depressions. Econometrica vol. 1; 1933;

FOBE, Nicole Julie. O Bitcoin como moeda paralela - uma visão econômica e a multiplicidade de desdobramentos jurídicos. Dissertação (mestrado) - Escola de Direito de São Paulo da Fundação Getúlio Vargas. 2016;

FRONTINI, Paulo Salvador. Títulos de Crédito e Títulos Circulatórios: que futuro a informática lhes reserva? Revista dos Tribunais, São Paulo, v. 85, n. 730, ago. 1996;

FUNDO MONETÁRIO INTERNACIONAL - FMI. Virtual Currencies and Beyond: Initial Considerations, $2016, \quad$ p. $17 . \quad$ Disponível http://www.imf.org/external/pubs/ft/sdn/2016/sdn1603.pdf. Acesso em: 15 out. 2020;

G20/OECD - Task Force on Financial Consumer Protection. G20/OECD High-Level Principles on Financial Consumer Protection. 2011. Disponível em: http://www.oecd.org/daf/fin/financial-markets/48892010.pdf Acesso em: 15 out. 2020; 
GALBRAITH, John Kenneth. Moeda: de onde veio, para onde foi. 2a ed. Livraria Pioneira: São Paulo, 1983;

GANS, Joshua S. The Fine Print in Smart Contracts. National Bureau of Economic Research. Cambridge, Working Paper 25443, jan. 2019. Disponível em: http://www.nber.org/papers/w25443. Acesso em: 15 out. 2020;

GARNER, Bryan. A. BLACKS LAW DICTIONARY. 9. ed. St. Paul: West Publishing Co., 2009;

GEIST, Michael. Consumer Protection and Licensing Regimes Review: The Implications of Electronic Commerce. in Ontario Ministry of Consumer \& Commercial Relations, (21 p.), 1999;

GEIST, Michael. Is there a there there? Toward greater certainty for Internet Jurisdiction. In: Berkeley Technology Law Journal, vol. 16, p. 1345-1406, 2002;

GLASER, Florian; BEZZENBERGER, Luis. Beyond Cryptocurrencies - A Taxonomy of Decentralized Consensus Systems. ECIS Completed Research Papers, [s.1], n. 57, p. 1/18, 2015;

Global Bitcoin Nodes Distribution. Disponível em: https://bitnodes.io/\#global-bitcoin-nodesdistribution. Acesso em: 27 jun.2020;

GONÇALVES, Guilherme Leite; VILLA BÔAS FILHO, Orlando, Teoria dos Sistemas Sociais - Direito e Sociedade na Obra de Niklas Luhmann. São Paulo: Saraiva, 2013;

GOSAR, Paul. Crypto-Currency Act of 2020 (Draft). Disponível em: https://drive.google.com/viewerng/viewer?url=https://2d234e5a-16a9-46ce-94e3029a82f36bf9.filesusr.com/ugd/be4f79 b7c2ff84879140f98023ed89a166bc41.pdf. Acesso em: 15 out. 2020 ;

GRIN. Disponível em: https://grin.mw/. Acesso em: 15 out. 2020.

GRINBERG, Reuben. Bitcoin: an Innovative Alternative Digital Currency. Hastings Science \& Technology Law Journal; 2011. Disponível em: http://www.meansofexchange.com/wp-content/uploads/2013/07/Bitcoin-InnovativeAlternative.pdf. Acesso em: 15 out. 2020;

GRUPENMACHER, Giovana Treiger. As plataformas de negociação de criptoativos: uma análise comparativa com as atividades das corretoras e da Bolsa sob a perspectiva da proteção do investidor e da prevenção à lavagem dinheiro. Dissertação (mestrado) Fundação Getulio Vargas, Escola de Direito de São Paulo. 2019;

GUDIN, Eugenio. Princípios da economia monetária. 7. ed. Rio de Janeiro: Agir, Vol. I. 1970;

GUPTA, Diksha; SAIA, Jared; YOUNG, Maxwell. Proof of Work Without All the Work. ICDCN'18: 19th International Conference on Distributed Computing and Networking, January 
4-7, 2018, Varanasi, India. ACM, New York, NY, USA, 2018. Disponível em https://doi.org/10.1145/3154273.3154333. Acesso em: 15 out. 2020;

HARARI, Yuval Noah. Sapiens - Uma breve história da humanidade. Trad. Janaína Marcoantonio. 23 ${ }^{\text {a }}$ ed. Ed L\&PM, Porto Alegre, 2017;

HAYEK, Friedrich. Denationalisation of Money: The Argument Refined. 5. ed. Londres: The Institute of Economic Affairs, 1990. 146 p. Disponível em: https://mises.org/system/tdf/Denationalisation of Money The Argument Refined_5.pdf?file=1\&type=document. Acesso em: 15 out. 2020;

HESSE, Rafael. Avaliação de tempos e custos Transacionais com uso do Blockchain como substituto de um agente intermediador. Trabalho de Conclusão do Curso de Graduação em Engenharia de Produção) - Escola Politécnica, Universidade de São Paulo, São Paulo, 2018;

HYPERLEDGER. Deutsche Börse Group Hyperledger Case Study. 2017. Disponível em: https://www.hyperledger.org/wp-

content/uploads/2018/03/Hyperledger CaseStudy DeutscheBorse FINAL.pdf. Acesso em: 15 out. 2020;

INTERNATIONAL MONETARY FUND - IMF. Programa de Avaliação do Setor Financeiro (FSAP). International Monetary Fund Factsheet. 2016. Disponível em: https://www.imf.org/external/lang/portuguese/np/exr/facts/fsapp.pdf. Acesso em: 15 out. 2020;

INTERNATIONAL ORGANIZATION OF SECURITIES COMMISSIONS - IOSCO. MoU MULTILATERAL MEMORANDUM OF UNDERSTANDING CONCERNING CONSULTATION AND COOPERATION AND THE EXCHANGE OF INFORMATION. 2002 rev. 2012. Disponível em: https://www.iosco.org/library/pubdocs/pdf/IOSCOPD386.pdf. Acesso em: 15 out. 2020;

INTERNATIONAL ORGANIZATION OF SECURITIES COMMISSIONS - IOSCO. Objectives and Principles of Securities Regulation. 2017. Disponível em: https://www.iosco.org/library/pubdocs/pdf/IOSCOPD561.pdf. Acesso em: 15 out. 2020;

JUSTEN FILHO, Marçal. O Direito Regulatório. In: GUIMARÃES, Edgar. Cenários do Direito Administrativo. Belo Horizonte: Fórum, 2004;

KAPLANOV, Nikolei. Nerdy Money: Bitcoin the private digital currency, and the case against its regulation. Temple University Legal Studies Research Paper; 2012. Disponível em: https://papers.ssrn.com/sol3/papers.cfm?abstract_id=2115203. Acesso em: 15 out. 2020;

LACKOFF. George; JOHNSON, Mark. Metaphors we live by. The University of Chicago Press, 2003;

LEÃES, Luiz Gastão Paes de. O conceito de "security" no direito norte-americano, e o conceito análogo no direito brasileiro. Revista de Direito Mercantil, Industrial, Econômico e Financeiro, São Paulo, n. 15, 1974;

LEONARDI, Marcel. Responsabilidade civil dos provedores de serviços de Internet. São Paulo: Juarez de Oliveira, 2005; 
LEONARDI, Marcel. Tutela e Privacidade na Internet. São Paulo: Saraiva, 2012;

LESSIG, Lawrence. Code and Other Laws of Cyberspace: Version 2.0. New York: Basic Books, 2006;

LESSIG, Lawrence. Free culture: how big media uses technology and the law to lock down culture and control creativity. Londres: Penguin Press, 2004;

LESSIG, Lawrence. The future of ideas: fate of the commons in a connected world. New York: Random House, 2001;

LÉVY, Pierre. A Inteligência Coletiva: por uma antropologia do ciberespaço, São Paulo: Edições Loyola, 2007;

LÉVY, Pierre. As Tecnologias da Inteligência - o futuro do pensamento na era da informática, Rio de Janeiro: Editora 34, 1993;

LÉVY, Pierre. Cibercultura, Rio de Janeiro: Editora 34, 1999;

LÉVY, Pierre. O Que é o Virtual? Rio de Janeiro: Editora 34, 1996;

LIBRA. Disponível em: https://libra.org/en-US/white-paper/\#cover-letter. Acesso em: 15 out. 2020;

LIMA, Cíntia Rosa Pereira de. Validade e obrigatoriedade dos contratos de adesão eletrônicos (shrink-wrap e click-wrap) e dos termos e condições de uso (browse-wrap). Tese de Doutorado defendida na Faculdade de Direito do Largo São Francisco. São Paulo, 2009. $673 \mathrm{p}$.

LORENZETTI, Ricardo Luis. Comercio Electrónico, Abeledo-Perrot, Buenos Aires, 2001;

LORENZETTI, Ricardo Luis. Informática, Cyberlaw, E-commerce, parte do livro Direito e Internet - Aspectos Jurídicos Relevantes. Coord. Newton De Lucca e Adalberto Simão Filho e outros, Bauru: EDIPRO, 2000;

LUHMANN, Niklas, Introdução à Teoria dos Sistemas (Aulas publicadas por J.T.Nafarrate). Petrópolis: Editora Vozes, 2009;

LUHMANN, Niklas. Legitimação pelo procedimento. Tradução de Maria da Conceição. Brasília: UNB, 1980;

LUHMANN, Niklas. Sistemas sociais: esboço de uma teoria geral. Petrópolis. Vozes. 2016;

LUHMANN, Niklas. Sociologia do Direito I. Rio de Janeiro: Tempo Brasileiro, 1983;

MAIA, Felipe Fernandes Ribeiro; ROCHA, Pedro Ernesto Gomes Rocha. Perspectivas jurídicas das criptomoedas: Desafios regulatórios no Brasil. Direito Tecnologia e Inovação v.I. PARENTONI, Leonardo [Coord.]. GONTIJO, Bruno Miranda; LIMA, Henrique Cunha Souza [Org.]. Belo Horizonte: Editora D’Plácido, 2019; 
MARANHÃO, Juliano. Inferências metafóricas e a reconfiguração do direito na era digital. Revista de Direito e as Novas Tecnologias. Ano 1, v. 1, out.- dez., 2018. [versão digital]. p. RR.5.3;

MARIAN, Omri Y. Are criptocurrencies super tax havens? University of Florida: Michingan Law Review First Impressions 38; 2013;

MARINHO, Maria Edelvacy Pinto; RIBEIRO, Gustavo Ferreira. A reconstrução da jurisdição pelo espaço digital: redes sociais, blockchain e criptomoedas como propulsores da mudança. Rev. Bras. Polít. Públicas, Brasília, v. 7, nº 3, 2017;

MARQUES, Cláudia Lima. Confiança no comércio eletrônico: um estudo dos negócios jurídicos de consumo no comércio eletrônico. São Paulo: Revista dos Tribunais, 2004;

MARTINS, Geraldo José Dolce Uzum. Avaliação do blockchain aplicado no processo de compras de uma organização. 2019. Dissertação (Mestrado em Engenharia de Produção) Escola Politécnica, Universidade de São Paulo, São Paulo, 2019;

MOELLER, Hans-Georg. The Radical Luhmann. Nova York: Columbia University Press, 2012;

MONERO. Disponível em: https://www.getmonero.org/. Acesso em 19 abr. 2019;

MOORE, John. Implementation, contracts, and renegotiation in environments with complete information. Advances in Economic Theory 1: p. 182-281, 1992;

MULLAINATHAN, Sendhil; THALER, Richard H. Behavioral Economics (October 2000).

NBER Working Paper No. w7948. Disponível em:
https://papers.ssrn.com/sol3/papers.cfm?abstract id=245733. Acesso em: 15 out. 2020;

NAJJARIAN, Ilene Patrícia de Noronha. Fintech Connection. Revista Jurídica LusoBrasileira. Lisboa, ano 6, n. 3, p.981-1003, 2020, p. 989.

NAJJARIAN, Ilene Patrícia de Noronha. O Crowdfunding e a Oferta Pública De Valores. Revista FMU Direito. São Paulo, ano 26, n. 37, p.48-55, 2012;

NAKAMOTO, Satoshi. Bitcoin: a peer-to-peer electronic cash system. Bitcoin.org; 2008. Disponível em: http://bitcoin.org/bitcoin.pdf. Acesso em: 15 out. 2020;

NASCENTES, Antenor. Tesouro da Fraseologia Brasileira, Rio de Janeiro: Ed. Nova Fronteira, 1986;

NERVA. Disponível em: https://getnerva.org/. Acesso em: 15 out. 2020;

NEVES, Rômulo Figueira. Acoplamento estrutural, fechamento operacional e processos sobrecomunicativos na teoria dos sistemas sociais de Niklas Luhmann. São Paulo, dissertação de mestrado, Faculdade de Filosofia, Letras e Ciências Humanas da Universidade de São Paulo. 2006; 
NOBEL PRIZE, Org. Richard H. Thaler- Facts. NobelPrize.org. Nobel Media AB, 2020. Disponível em: https://www.nobelprize.org/prizes/economic-sciences/2017/thaler/facts/. Acesso em: 15 out. 2020;

NORMAN, Alan T. Blockchain Technology Explained. Ed. Amazon, Londres, 2017;

OLIVEIRA, Marcos Cavalcante de. Moeda, Juros e Instituições Financeiras: Regime Jurídico. Rio de Janeiro. Ed. Forense, 2009;

PEOPLE'S BANK OF CHINA - PBC. Announcement of the Banking Regulatory Commission, the Securities Regulatory Commission and the Insurance Regulatory Commission of the General Administration of Industry and Commerce, the Ministry of Industry and Information Technology, the Central Network of the People's Bank of China on preventing the risk of issuing and financing tokens. Disponível em: www.pbc.gov.cn/goutongjiaoliu/113456/113469/3374222/index.html. Acesso em: 15 out. 2020;

PEOPLE'S BANK OF CHINA - PBC. Continued Prevention of the Risks in ICO and Virtual Currency trading. Disponível em: http://shanghai.pbc.gov.cn/fzhshanghai/113571/3629984/index.html. Acesso em: 15 out. 2020;

PEREZ, Marcelo Monteiro; FAMA, Rubens. Ativos intangíveis e o desempenho empresarial. Revista Contabilidade \& Finanças. São Paulo, v. 17, n. 40, p. 7-24, abr. 2006.

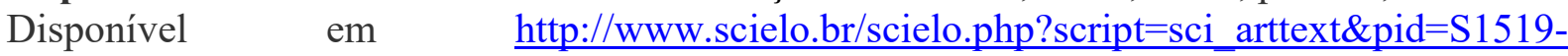
70772006000100002\&lng=pt\&nrm=iso. Acesso em: 15 out. 2020;

PERUGINI, Maria Letizia; MAIOLI, Cesare. Bitcoins: Tra Moneta Virtuale e Commodity Finanziaria. 2014. Disponível em: http://ssrn.com/abstract=2526207. Acesso em: 15 out. 2020;

PRATES, Daniela Magalhães. Crises Financeiras dos Países Emergentes: uma interpretação heterodoxa. Campinas: Universidade Estadual de Campinas; 2002;

PUPLAVA, James J; MATONIS, Jon. Bitcoin CryptoCurrency: Is "Digital Gold" the Future of Money? 2012. Disponível em: http://www.financialsense.com/financial-sensenewshour/guest-expert/2012/10/31/jon-matonis/bitcoin-crypto-currency-is-digital-gold-thefuture-of-money. Acesso em: 15 out. 2020;

RECEITA FEDERAL DO BRASIL. Instrução Normativa 1.888/2019. Institui e disciplina a obrigatoriedade de prestação de informações relativas às operações realizadas com criptoativos à Secretaria Especial da Receita Federal do Brasil. DOU 07 maio 2019. Disponível em: http://www.in.gov.br/en/web/dou/-/instru\%C3\%87\%C3\%83o-normativa-n\%C2\%BA-1.888de-3-de-maio-de-2019-87070039 . Acesso em: 15 out. 2020;

REINO UNIDO. Financial Conduct Authority - FCA. Regulatory sandbox November 2015. Disponível em: https://www.fca.org.uk/publication/research/regulatory-sandbox.pdf. Acesso em: 15 out. 2020 ; 
REINO UNIDO. Locomotive Act. $186 . \quad$ Disponível em: http://www.legislation.gov.uk/ukpga/Vict/24-25/70/section/1/enacted. Acesso em: 15 out. 2020;

REPUBLICA POPULAR DA CHINA. Ministério Do Comércio. China bars use of virtual money for trading in real goods. 2009. Disponível em: http://english.mofcom.gov.cn/aarticle/newsrelease/commonnews/200906/20090606364208.ht ml. Acesso em: 15 out. 2020;

REZZÓNICO, Juan Carlos. Principios fundamentales de los contratos. Buenos Aires: Astrea, 1999;

RIBEIRO, Aureo Lídio Moreira. Justificativa do Projeto de Lei $\mathbf{n}^{\mathbf{0}}$ 2.060/2019. Disponível em:https://www.camara.leg.br/proposicoesWeb/prop_mostrarintegra?codteor $=1728497 \&$ filen $\underline{\text { ame }=\mathrm{PL}+2060 / 2019}$. Acesso em: 15 out. 2020;

RODRIGUES, Carlo Kleber da Silva; SILVA, Paulo Caetano da. Uma Análise de Algoritmos de Consenso para Blockchain visando à Implementação de Sistemas de Informação Distribuídos Transparentes. Revista de Sistemas e Computação, Salvador, v. 9, n. 1, p. 163188, jan./jun. 2019. Disponível em: https://revistas.unifacs.br/index.php/rsc/article/view/5919 . Acesso em: 15 out. 2020;

RODRIGUES, Léo Peixoto; DA COSTA, Everton Garcia. Niklas Luhmann: uma visão sistêmica (e polêmica) da sociedade. Sociologias, Porto Alegre, ano 20, n. 48, maio-ago 2018;

RODRIGUES, Léo Peixoto; NEVES, Fabrício Monteiro. A sociologia de Niklas Luhmann. Petrópolis: Vozes, 2017;

RON, Dorit; SHAMIR, Adi. Quantitative Analysis of the Full Bitcoin Transaction Graph. Israel: The Weizmann Institute of Science; 2013;

SANDERS, Bernie. "SENATOR SANDERS AND CONGRESSMAN SHERMAN STAND TOGETHER TO REINTRODUCE "TOO BIG TO FAIL, TOO BIG TO EXIST ACT". States News Service. (October 3, 2018 Wednesday): 437 words. Nexis. Disponível em: https://sherman.house.gov/media-center/press-releases/senator-sanders-and-congressmansherman-stand-together-to-reintroduce. Acesso em: 15 out. 2020;

SANTANA, Maria Helena dos Santos Fernandes de; GUIMARÃES, Juliana Paiva. MERCADO DE VALORES MOBILIÁRIOS: EVOLUÇÃO RECENTE E TENDÊNCIAS. Revista de Direito Bancário e do Mercado de Capitais, SÃo Paulo, v. 8, p.483492, dez. 2008;

SECURITIES AND EXCHANGE COMMISSION - SEC. 2018. Disponível em: https://www.sec.gov/ICO. Acesso em: 15 out. 2020;

SECURITIES AND EXCHANGE COMMISSION - SEC. Framework for "Investment Contract" Analysis of Digital Assets. Disponível em: https://www.sec.gov/corpfin/framework-investment-contract-analysis-digital-assets\# edn1. Acesso em; 15 out. 2020. 
SECURITIES AND EXCHANGE COMMISSION - SEC. Leaders of CFTC, FinCEN, and SEC Issue Joint Statement on Activities Involving Digital Assets. 2019. Disponível em: https://www.sec.gov/news/public-statement/cftc-fincen-secjointstatementdigitalassets. Acesso em: 15 out. 2020 ;

SILVA, Alexandre Pacheco da. ASPECTOS TÉCNICOS DO FUNCIONAMENTO DO SISTEMA BITCOIN. in BARBOSA, Tatiana Casseb Bahr de Miranda et al. A REVOLUÇÃO DAS MOEDAS VIRTUAIS: BITCOINS E ALTCOINS. São Paulo: Revoar, 2016;

SZABO, Nick. Smart Contracts. [s.1], 1994. Disponível em: http://www.fon.hum.uva.nl/rob/Courses/InformationInSpeech/CDROM/Literature/LOTwinter school2006/szabo.best.vwh.net/smart.contracts.html. Acesso em: 15 out. 2020;

TANJI, Márcia. Mercado de capitais brasileiro e tutela coletiva dos interesses. Dissertação (Mestrado em Direito Comercial) - Faculdade de Direito, Universidade de São Paulo, São Paulo, 2009;

THALER, Richard. H. Misbehaving: The making of behavioral economics. New York: W. W. Norton \& Company. 2015;

THALER, Richard. H. Mental Accounting and Consumer Choice, Marketing Science 4, [s.1.], p. 199-214, 1985;

THALER, Richard; SUNSTEIN, Cass Robert. Nudge: Improving Decisions about Health, Wealth, and Happiness, Yale University Press, 2008;

ULRICH, Fernando. BITCOIN: A MOEDA NA ERA DIGITAL. São Paulo: Instituto Ludwig von Mises Brasil, $2014 . \quad$ Disponível em: https://jornalggn.com.br/sites/default/files/documentos/fernando-ulrich-bitcoin171212104741.pdf. Acesso em: 15 out. 2020;

UNIÃO EUROPEIA. Directive (EU) 2018/843 - AMLD5. Disponível em: https://eurlex.europa.eu/legal-content/EN/TXT/?uri=CELEX\%3A32018L0843. Acesso em: 15 out. 2020;

UNIÃO EUROPEIA. Directive 2014/65/EU of the European Parliament and of the Council of 15 May 2014 on markets in financial instruments. Disponível em: https://eurlex.europa.eu/legal-content/EN/TXT/?uri=CELEX:02014L0065-20200326 . Acesso em: 15 out. 2020;

UNSGSA FinTech Working Group and CCAF. Early Lessons on Regulatory Innovations to Enable Inclusive FinTech: Innovation Offices, Regulatory Sandboxes, and RegTech. Office of the UNSGSA and CCAF: New York, NY. 2019;

VARELA, Dyjann Müller Aguiar. Do Conceito Jurídico da E-Moeda. Revista de Direito UNIFACEX, Natal-RN, v.5, n.1, 2014. ISSN: 2179-216X. Paper avaliado pelo sistema blind review, recebido em 27 de novembro, 2014; Aprovado em 22 de abril, 2015. Disponível em: https://periodicos.unifacex.com.br/direito/article/viewFile/543/163. Acesso em: 15 out. 2020;

VERTCOIN. Disponível em: https://vertcoin.org/. Acesso em: 15 out. 2020; 
VILLASENOR, John; MONK, Cody; BRONK, Christopher. Shadowy Figures: Tracking Illicit Financial Transactions in the Murky World of Digital Currencies, Peer-to-Peer Networks and Mobile Devices Payments. Center for Technology Innovation at Brookings and Rice University, 2011;

VIVANTE, Cesare. Trattato di Diritto Commerciale. 5. a edição, vol. III, Ed. Francesco Vallardi, Milão, 1935;

WALD, Arnoldo. O mercado futuro de índices e os valores mobiliários. Revista de Direito Mercantil, Industrial, Econômico e Financeiro, São Paulo, n. 57, 1985;

WALTON, Douglas. Argument from analogy in legal rhetoric. Artificial Intelligence and Law, v. 21 (3), 2013;

White Paper Cryptau. 2020. Disponível em: https://cryptau.io/wpcontent/uploads/2020/06/WhitePaper_Cryptau_v1.8.pdf. Acesso em: 15 out. 2020;

WINTER, Steven L. A clearing in the forest: law, life and mind. University of Chicago Press, 2001;

WORLD BANK. Financial Sector Assessment Program (FSAP). Disponível em: https://www.worldbank.org/en/programs/financial-sector-assessment-program\#1. Acesso em: 15 out. 2020

WRIGHT, Aaron; DE FILIPPI, Primavera, Decentralized Blockchain Technology and the Rise of Lex Cryptographia, 2015. Disponível em: https://ssrn.com/abstract=2580664. Acesso em: 15 out. 2020 ;

YAZBEK, Otavio. AUTORREGULAÇÃO NO MERCADO DE CAPITAIS NO BRASIL. In: COELHO, Fabio Ulhoa (org.). TRATADO DE DIREITO COMERCIAL. São Paulo: Saraiva, 2014;

ZCASH. Disponível em: https://z.cash/pt/. Acesso em: 15 out. 2020. 